\title{
Immunohistochemical over expression of p53 in head and neck Squamous cell carcinoma: clinical and prognostic significance
}

\author{
Atif Ali Hashmi ', Zubaida Fida Hussain ${ }^{1}$, Shumaila Kanwal Hashmi², Muhammad Irfan' ${ }^{1}$, Erum Yousuf Khan ${ }^{1}$, \\ Naveen Faridi ${ }^{1}$, Amir Khan ${ }^{3^{*}}$ and Muhammad Muzzammil Edhi ${ }^{4}$
}

\begin{abstract}
Objective: Immunohistochemical over expression of p53 is considered as a marker of poor prognosis in many cancers. Therefore, we aimed to evaluate immunohistochemical overexpression of p53 in 121 cases of head and neck Squamous cell carcinoma and its association with various clinicopathologic features and survival.

Results: Total 66.1\% (80 cases) expressed positive p53 expression, 34\% (29 cases) revealed no p53 expression, while focal positive p53 expression was noted in 9.9\% (12 Cases). Moreover, high p53 expression (> 70\%) was noted in $26.4 \%$ (32 cases), while 19\% (23 cases) showed 51-70\% p53 expression. On the basis of intensity of p53 staining; strong p53 expression was noted in 39.7\% (48 cases), while $24.8 \%$ (30 cases) and 10.7\% (13 cases) revealed intermediate and weak p53 expression respectively. Significant association of p53 intensity of expression with extranodal extension and higher tumor grade (grades II and III) was noted. p53 is useful prognostic biomarker in head and neck Squamous cell carcinoma and therefore we suggest that more large scale studies are needed to evaluate its prognostic significance in our population.
\end{abstract}

Keywords: Head and Squamous cell carcinoma, Oropharyngeal Squamous cell carcinoma, p53, Areca nut, Gutka

\section{Introduction}

Despite advancements in cancer treatment, head and neck Squamous cell carcinoma (HNSCC) remains significant cause of morbidity and mortality worldwide, and hence 5 years survival rate is still below $50 \%[1,2]$. Owing to the widespread use of chewing tobacco and areca nut (pan/gutka) in South-Asia, oropharyngeal Squamous cell carcinoma (OSCC) is on a rise in this part of the world [3]. Oral carcinogenesis is a multistep process involving multiple proto-oncogenes and tumor suppressor genes including p16, cyclin D1, p53 and EGFR. TP53 is a tumor suppressor gene located on chromosome 17p. Mutations of TP53 gene is one of the most common event in human carcinogenesis. As mutated protein is not easily digestible, therefore it accumulates inside the cancer cell leading

\footnotetext{
*Correspondence: dramirkhan04@gmail.com

${ }^{3}$ Kandahar University, Kandahar 3802, Afghanistan

Full list of author information is available at the end of the article
}

to immunohistochemical overexpression. p53 overexpression in OSCC is considered a marker of poor prognosis [4]. Moreover, p53 overexpression may result in decreased sensitivity of tumor cells to chemotherapeutic drugs [5]. Therefore, we aimed to evaluate immunohistochemical overexpression of p53 in our cases of HNSCC and its association with various clinicopathologic features and survival so that therapeutic protocols could be devised for loco-regional population.

\section{Main text \\ Patients and methods}

This was a retrospective study in which, 144 cases of HNSCC excision specimens were identified from previous records of pathology department. All patients had elective surgeries at Liaquat National hospital, Karachi from January 2008 till December 2013 over a period of 7 years. The approval of the study was taken from research and ethical review committee of the institution. 
Table 1 Clinicopathologic features of Squamous cell carcinoma head and neck $(n=144)$

\begin{tabular}{|c|c|c|}
\hline Characteristic & Frequency & Percentage (\%) \\
\hline Age $(\text { years })^{\mathrm{a}}$ & $51.28 \pm 12.14$ & \\
\hline \multicolumn{3}{|l|}{ Age groups (years) } \\
\hline$\leq 30$ & 6 & 4.2 \\
\hline $31-50$ & 72 & 50 \\
\hline$>50$ & 66 & 45.8 \\
\hline \multicolumn{3}{|l|}{ Gender } \\
\hline Male & 106 & 73.6 \\
\hline Female & 38 & 26.4 \\
\hline \multicolumn{3}{|l|}{ Histological subtypes } \\
\hline Non-keratinizing & 20 & 13.9 \\
\hline Keratinizing & 85 & 59 \\
\hline Non-keratinizing with maturation & 39 & 27.1 \\
\hline \multicolumn{3}{|l|}{ Histologic grade } \\
\hline Grade-I & 39 & 27.1 \\
\hline Grade-II & 89 & 61.8 \\
\hline Grade-III & 16 & 11.1 \\
\hline \multicolumn{3}{|l|}{ Location of tumor } \\
\hline Oral cavity & 96 & 66.7 \\
\hline Lip & 3 & 2.1 \\
\hline Tongue & 39 & 27.1 \\
\hline Soft palate & 6 & 4.2 \\
\hline Tumor size $(\mathrm{cm})^{\mathrm{a}}$ & $3.26 \pm 1.67$ & \\
\hline \multicolumn{3}{|l|}{ Tumor stage } \\
\hline $\mathrm{T} 1$ & 35 & 24.3 \\
\hline $\mathrm{T} 2$ & 72 & 50 \\
\hline $\mathrm{T} 3 / \mathrm{T} 4$ & 37 & 25.7 \\
\hline Tumor depth $(\mathrm{cm})^{\mathrm{a}}$ & $1.14 \pm 0.78$ & \\
\hline \multicolumn{3}{|l|}{ Depth of invasion (cm) } \\
\hline$<2$ & 121 & 84 \\
\hline$\geq 2$ & 23 & 16 \\
\hline \multicolumn{3}{|l|}{ Nodal stage } \\
\hline NO & 76 & 52.8 \\
\hline $\mathrm{N} 1$ & 20 & 13.9 \\
\hline $\mathrm{N} 2 \mathrm{a}$ & 0 & 0 \\
\hline $\mathrm{N} 2 \mathrm{~b}$ & 43 & 29.9 \\
\hline $\mathrm{N} 2 \mathrm{C}$ & 4 & 2.8 \\
\hline N3 & 1 & 0.7 \\
\hline \multicolumn{3}{|l|}{ Extra nodal extension } \\
\hline Not present & 109 & 75.7 \\
\hline Present & 35 & 24.3 \\
\hline \multicolumn{3}{|l|}{ Lymphovascular invasion } \\
\hline Not present & 142 & 98.6 \\
\hline Present & 2 & 1.4 \\
\hline \multicolumn{3}{|l|}{ Perineural invasion } \\
\hline Not present & 124 & 86.1 \\
\hline Present & 20 & 13.9 \\
\hline \multicolumn{3}{|l|}{ Radiation $(n=86)$} \\
\hline Yes & 35 & 60.3 \\
\hline No & 23 & 39.7 \\
\hline
\end{tabular}

Table 1 (continued)

\begin{tabular}{lll}
\hline Characteristic & Frequency & Percentage (\%) \\
\hline $\begin{array}{ll}\text { Chemotherapy }(n=86) \\
\text { Yes }\end{array}$ & 34 & 58.6 \\
No & 24 & 41.4 \\
Recurrence $(n=86)$ & 33 & 56.9 \\
Yes & 25 & 43.1 \\
No & & \\
History of pan $(n=57)$ & 34 & 59.6 \\
Yes & 23 & 40.4 \\
No & & \\
History of smoking $(n=57)$ & 4 & 7 \\
Yes & 53 & 93 \\
No & & \\
History of alcohol $(n=57)$ & 1 & 1.8 \\
Yes & 56 & 98.2 \\
No & & \\
\hline Mean + SD
\end{tabular}

${ }^{a}$ Mean \pm SD

Informed written consent was taken from all of the patients. Hematoxylin and eosin stained slides of all cases and paraffin blocks of 77 cases were recruited and new sections were cut when felt necessary. Slides of all cases were evaluated by two senior histopathologists independently and pathologic characteristics like tumor type, grade, tumor-stage, nodal-stage, lymphovascular invasion and perineural were interpreted. Clinical records of 57 patients were available and are thus reviewed from institutional records to evaluated patients age, smoking, alcohol and gutka/pan use history, history of radiation and chemotherapy. Moreover, representative tissue blocks of 121 cases were available for $\mathrm{p} 53$ immunohistochemistry.

\section{Immunohistochemistry}

p53 IHC was performed using DAKO EnVision method using DAKO anti-human p53 protein, clone DO-7 according to manufacturers protocol. Nuclear staining for p53 was both quantitatively and qualitatively evaluated. Intensity of staining was grouped into no staining (0), weak $(1+)$, intermediate $(2+)$, strong $(3+)$ while percentage of positively stained cells were calculated as a continuous variable. Intermediate to strong staining in more than $10 \%$ cancer cells was taken as positive while weak to intermediate staining in less than $10 \%$ tumor cells was interpreted as focal positive (Additional file 1: Figure S1). No staining in cancer cells was taken as negative. Moreover, p53 immunostaining was also categorized according to percentage of staining cells into different groups. 


\section{Statistical analysis}

Statistical package for social sciences (SPSS 21) was used for data compilation and analysis. Mean and standard deviation were evaluated for quantitative variables. For qualitative variables, frequency and percentage were calculated. Chi square was applied to determine association. $P$ value of $\leq 0.05$ was considered as significant. Statistical power of each variable was calculated by using software PASS version 11. Power of each tested variable is mentioned in Tables 2 and 3.

\section{Demographic profile of patients}

Mean age of the patients included in our study was found to be $51.28 \pm 12.14$. Most common age group was between 31 and 50 years. Male gender was more common. Oral cavity was the most common origin of SCC found in our study (96 cases). High tumor stage (T3/T4) was noted in 25\% (37 cases). Mean tumor size was $3.26 \pm 1.67 \mathrm{~cm}$ while mean tumor depth was found to be $1.14 \pm 0.78 \mathrm{~cm}$. High nodal stage $(\mathrm{N} 2 / \mathrm{N} 3)$ was seen in $34.4 \%$ cases. 85 cases revealed keratinizing phenotype, while $11.1 \%$ cases were of high grade (grade III). Perineural and lymphovascular invasion was seen in 13.9 and $1.4 \%$ cases respectively as represented in Table 1.

\section{Immunohistochemical expression of p53 in head and neck Squamous cell carcinoma}

Total $66.1 \%$ (80 cases) expressed positive p53 expression, $34 \%$ (29 cases) revealed no p53 expression, while focal positive p53 expression was noted in 9.9\% (12 Cases).

Table 2 Association of p53 over expression categories with clinic pathologic parameters of head and neck Squamous cell carcinoma

\begin{tabular}{|c|c|c|c|c|c|c|c|}
\hline & \multicolumn{5}{|l|}{ n (\%) } & \multirow[t]{2}{*}{$P$ value } & \multirow[t]{2}{*}{ Power of test (\%) } \\
\hline & $\leq 10 \%(n=43)$ & $11-50 \%(n=23)$ & $51-70 \%(n=23)$ & $>70 \%(n=32)$ & Total $(n=121)$ & & \\
\hline \multicolumn{8}{|l|}{ Age group (years) } \\
\hline$\leq 30$ & $3(7)$ & $0(0)$ & $1(4.3)$ & $1(3.1)$ & $5(4.1)$ & 0.502 & 37.12 \\
\hline $31-50$ & $23(53.5)$ & $8(34.8)$ & $10(43.5)$ & $17(53.1)$ & $58(47.9)$ & & \\
\hline$>50$ & $17(39.5)$ & $15(65.2)$ & $12(52.2)$ & $14(43.8)$ & $58(47.9)$ & & \\
\hline \multicolumn{8}{|l|}{ Gender } \\
\hline Male & $36(83.7)$ & $15(65.2)$ & $16(69.6)$ & $22(68.8)$ & 89 (73.6) & 0.299 & 33.12 \\
\hline Female & $7(16.3)$ & $8(34.8)$ & $7(30.4)$ & $10(31.3)$ & $32(26.4)$ & & \\
\hline \multicolumn{8}{|c|}{ Depth of invasion (cm) } \\
\hline$<2$ & $36(83.7)$ & $17(73.9)$ & $23(100)$ & $26(81.3)$ & $102(84.3)$ & 0.056 & 54.7 \\
\hline$\geq 2$ & $7(16.3)$ & $6(26.1)$ & $0(0)$ & $6(18.8)$ & $19(15.7)$ & & \\
\hline \multicolumn{8}{|l|}{ Nodal stage } \\
\hline No & $26(60.5)$ & $16(69.6)$ & $12(52.2)$ & $13(40.6)$ & $67(55.4)$ & 0.258 & 65.64 \\
\hline N1 & $8(18.6)$ & $1(4.3)$ & $3(13)$ & $6(18.8)$ & $18(14.9)$ & & \\
\hline $\mathrm{N} 2 \mathrm{a}$ & $0(0)$ & $0(0)$ & $0(0)$ & $0(0)$ & $0(0)$ & & \\
\hline $\mathrm{N} 2 \mathrm{~b}$ & $9(20.9)$ & $5(21.7)$ & $7(30.4)$ & $11(34.4)$ & $32(26.4)$ & & \\
\hline $\mathrm{N} 2 \mathrm{C}$ & $0(0)$ & $0(0)$ & $1(4.3)$ & $2(6.3)$ & $3(2.5)$ & & \\
\hline N3 & $0(0)$ & $1(4.3)$ & $0(0)$ & $0(0)$ & $1(0.8)$ & & \\
\hline \multicolumn{8}{|l|}{ Histological subtypes } \\
\hline Non-keratinizing & $3(7)$ & $1(4.3)$ & $4(17.4)$ & $10(31.3)$ & $18(14.9)$ & 0.100 & 71.32 \\
\hline Keratinizing & $28(65.1)$ & $15(65.2)$ & $12(52.2)$ & $14(43.8)$ & $69(57)$ & & \\
\hline $\begin{array}{l}\text { Non-keratinizing } \\
\text { with maturation }\end{array}$ & $12(27.9)$ & $7(30.4)$ & $7(30.4)$ & $8(25)$ & $34(28.1)$ & & \\
\hline \multicolumn{8}{|l|}{ Histologic grade } \\
\hline Grade-I & $13(30.2)$ & $11(47.8)$ & $5(21.7)$ & $4(12.5)$ & $33(27.3)$ & 0.065 & 74.37 \\
\hline Grade-II & $24(55.8)$ & $11(47.8)$ & $13(56.5)$ & $25(78.1)$ & $73(60.3)$ & & \\
\hline Grade-III & $6(14)$ & $1(4.3)$ & $5(21.7)$ & $3(9.4)$ & $15(12.4)$ & & \\
\hline \multicolumn{8}{|l|}{ Perineural invasion } \\
\hline Not present & $39(90.7)$ & $22(95.7)$ & $21(91.3)$ & $23(71.9)$ & $105(86.8)$ & 0.051 & 69.81 \\
\hline Present & $4(9.3)$ & $1(4.3)$ & $2(8.7)$ & $9(28.1)$ & $16(13.2)$ & & \\
\hline
\end{tabular}

Chi square test was applied

$\mathrm{P}$-value $\leq 0.05$ considered as significant 
Table 3 Association of p53 expression intensity with clinicopathologic parameters of head and neck Squamous cell carcinoma

\begin{tabular}{llllll}
$n(\%)$ & & & P-value & Power of test (\%) \\
\hline $\begin{array}{l}\text { No intensity } \\
(n=30)\end{array}$ & Weak $(n=13)$ & $\begin{array}{l}\text { Intermediate } \\
(n=30)\end{array}$ & Strong $(n=48)$ & Total $(n=121)$ &
\end{tabular}

\begin{tabular}{|c|c|c|c|c|c|c|c|}
\hline \multicolumn{8}{|c|}{ Age group (years) } \\
\hline$\leq 30$ & $3(10)$ & $0(0)$ & $1(3.3)$ & $1(2.1)$ & $5(4.1)$ & 0.445 & 43.47 \\
\hline $31-50$ & $15(50)$ & $8(61.5)$ & $11(36.7)$ & $24(50)$ & $58(47.9)$ & & \\
\hline$>50$ & $12(40)$ & $5(38.5)$ & $18(60)$ & $23(47.9)$ & $58(47.9)$ & & \\
\hline \multicolumn{8}{|l|}{ Gender } \\
\hline Male & 25 (83.3) & $11(84.6)$ & $22(73.3)$ & $31(64.6)$ & $89(73.6)$ & 0.269 & 38.17 \\
\hline Female & $5(16.7)$ & $2(15.4)$ & $8(26.7)$ & $17(35.4)$ & $32(26.4)$ & & \\
\hline \multicolumn{8}{|l|}{ Nodal stage } \\
\hline No & $17(56.7)$ & $9(69.2)$ & $22(73.3)$ & 19 (39.6) & $67(55.4)$ & 0.053 & 82.44 \\
\hline N1 & $8(26.7)$ & $0(0)$ & $2(6.7)$ & $8(16.7)$ & $18(14.9)$ & & \\
\hline $\mathrm{N} 2 \mathrm{a}$ & $0(0)$ & $0(0)$ & $0(0)$ & $0(0)$ & $0(0)$ & & \\
\hline $\mathrm{N} 2 \mathrm{~b}$ & $5(16.7)$ & $4(30.8)$ & $6(20)$ & $17(35.4)$ & $32(26.4)$ & & \\
\hline $\mathrm{N} 2 \mathrm{C}$ & $0(0)$ & $0(0)$ & $0(0)$ & $3(6.3)$ & $3(2.5)$ & & \\
\hline N3 & $0(0)$ & $0(0)$ & $0(0)$ & $1(2.1)$ & $1(0.8)$ & & \\
\hline \multicolumn{8}{|c|}{ Extranodal extension } \\
\hline Not present & $22(73.3)$ & $11(84.6)$ & $28(93.3)$ & $29(60.4)$ & $90(74.4)$ & 0.008 & 81.53 \\
\hline Present & $8(26.7)$ & $2(15.4)$ & $2(6.7)$ & 19 (39.6) & $31(25.6)$ & & \\
\hline \multicolumn{8}{|c|}{ Histologic grade } \\
\hline Grade-I & $6(20)$ & $7(53.8)$ & $12(40)$ & $8(16.7)$ & $33(27.3)$ & 0.046 & 74.91 \\
\hline Grade-II & $20(66.7)$ & $4(30.8)$ & $14(46.7)$ & 35 (72.9) & $73(60.3)$ & & \\
\hline Grade-III & $4(13.3)$ & $2(15.4)$ & $4(13.3)$ & $5(10.4)$ & $15(12.4)$ & & \\
\hline
\end{tabular}

Chi square test was applied

P-value $\leq 0.05$ considered as significant

Moreover, high p53 expression (>70\%) was noted in $26.4 \%$ (32 cases), while $19 \%$ (23 cases) showed $51-70 \%$ p53 expression. $11-50$ and $<10 \% /$ no expression was noted in $19 \%$ ( 23 cases) and $35.5 \%$ (43 cases) respectively. On the basis of intensity of p53 staining; strong p53 expression was noted in $39.7 \%$ (48 cases), while $24.8 \%$ (30 cases) and $10.7 \%$ (13 cases) revealed intermediate and weak p53 expression respectively. Tables 2 and 3 represent association of p53 expression with various clinicopathologic parameters in HNSCC. Significant association of p53 intensity of expression with extranodal extension and higher tumor grade (grades II and III) was noted. Association with those clinicopathological parameters with statistical power of less than 50 were not included in Tables 2 and 3.

\section{Discussion}

In the present study, we found that $66.1 \%$ of HNCC revealed p53 overexpression; moreover significant association of p53 was noted with extranodal extension and tumor grade, which are key prognostic factors of
HNSCC, thus proving the prognostic significance of this biomarker.

p53 overexpression in HNSCC varies in different parts of the world, owing to divergent risk factors and pathogenesis of the disease. Kerdpon et al. reported a positive association of alcohol use with p53 over expression and negative association with betal nut and tobacco [6]. P53 expression in HNSCC ranges from 25 to $90 \%$. Dragomir et al. reported 31\% p53 expression [7], whereas, Gonzalez-Moles revealed 57.7\% expression of p53 [8]. On the other hand, $85.6 \% \mathrm{p} 53$ expression was reported in a study from India [5], 63.3\% expression was noted in a research conducted in Brazilian population [9], while as low as $28.5 \%$ expression was noted in a study conducted in Iran [10]. Varied expression of p53 in HNSCC may be due to different use of techniques, methods of interpretation or due to difference in ethnicity and risk factors involved in HNSCC pathogenesis. Previous literature also showed association of p53 expression with tumor grade and other histologic features. Dave et al. in a study involving 40 cases of HNCC found a significant association of p53 expression with tumor grade and other histologic 
parameters like degree of keratinization [11]. Although we found significant association of p53 expression with tumor grade, however association with other histologic parameters was not noted. Although no significant association was noted between $\mathrm{p} 53$ expression and other clinicopathological parameters in our study, however as the statistical power for these associations was less than $50 \%$ therefore, no conclusion could be derived.

Many studies have proved the prognostic significance of p53 in HNCC, owing to association of p53 overexpression with overall survival, recurrence, high tumor grade and $\mathrm{T}$ and $\mathrm{N}$ stage $[5,8,12]$. Conversely, a meta-analysis involving 174 studies revealed no association of p53 overexpression as a marker of poor prognosis [13]. We found a significant association of intensity of p53 expression with extranodal extension and tumor grade, with a large sample size and significant statistical power the associations are important; therefore we suggest more large scale studies to evaluate prognostic significance of p53 expression in HNSCC and its association with disease free survival in loco-regional population.

\section{Limitation}

Major limitation of the study was that, this was a single center data, however as it's a major tertiary care hospital of the province therefore the results may have major clinical implications. Furthermore, recurrence status of patients was not available to evaluate association p53 expression with disease free survival.

\section{Additional file}

Additional file 1: Figure S1. p53 expression in oral Squamous cell carcinoma.

\section{Abbreviations \\ HNSCC: head and neck Squamous cell carcinoma; OSCC: oropharyngeal Squamous cell carcinoma.}

\section{Authors' contributions}

$\mathrm{AAH}$ and $\mathrm{ZFH}$ : main author of manuscript, have made substantial contributions to conception and design of study. SKH, MI, EYK, NF, AK and MME: have been involved in requisition and analysis of the data and revision of the manuscript. All authors read and approved the final manuscript.

\section{Author details}

${ }^{1}$ Liaquat National Hospital and Medical College, Karachi, Pakistan. ${ }^{2} \mathrm{CMH}$ Multan Institute of Medical Sciences, Multan, Pakistan. ${ }^{3}$ Kandahar University, Kandahar 3802, Afghanistan. ${ }^{4}$ Brown University, Providence, RI, USA.

\section{Acknowledgements}

We gratefully acknowledge all staff members of Pathology, Liaquat National Hospital, Karachi, Pakistan for their help and cooperation.

\section{Competing interests}

The authors declare that they have no competing interests.

\section{Availability of data and materials}

Please contact author, Atif Ali Hashmi (doc_atif2005@yahoo.com) for data requests.

\section{Consent to publish}

Not applicable.

\section{Ethics approval and consent to participate}

Ethics committee of Liaquat National Hospital, Karachi, Pakistan approved the study. Written informed consent was obtained from the patients for the participation.

\section{Funding}

There was no funding available for this manuscript.

\section{Publisher's Note}

Springer Nature remains neutral with regard to jurisdictional claims in published maps and institutional affiliations.

Received: 2 April 2018 Accepted: 27 June 2018

Published online: 03 July 2018

\section{References}

1. Ferlay J, Shin HR, Bray F, Forman D, Mathers C, Parkin DM. GLOBOCAN 2008, Cancer Incidence and Mortality Worldwide: IARC CancerBase No. 10. Lyon: International Agency for Research on Cancer; 2010.

2. Warnakulasuriya S. Global epidemiology of oral and oropharyngeal cancer. Oral Oncol. 2009;45:309-16.

3. Gupta N, Gupta R, Acharya AK, Patthi B, Goud V, Reddy S, Garg A, Singla A. Changing trends in oral cancer-a global scenario. Nepal J Epidemiol. 2017;6(4):613-9.

4. Abbas NF, Labib El-Sharkawy S, Abbas EA, El-Shaer AM. Immunohistochemical study of p53 and angiogenesis in benign and preneoplastic oral lesions and oral squamous cell carcinoma. Oral Surg Oral Med Oral Pathol Oral Radiol Endod. 2007;103:385-90.

5. Khan H, Gupta S, Husain N, Misra S, Mps N, Jamal N, Ghatak A. Correlation between expressions of cyclin-D1, EGFR and p53 with chemoradiation response in patients of locally advanced oral squamous cell carcinoma. BBA Clin. 2014;21(3):11-7.

6. Kerdpon D, Sriplung H, Kietthubthew S. Expression of p53 in oral squamous cell carcinoma and its association with risk habits in southern Thailand. Oral Oncol. 2001;37(7):553-7.

7. Dragomir LP, Simionescu C, Mărgăritescu C, Stepan A, Dragomir IM, Popescu MR. P53, p16 and Ki67 immuno expression in oral squamous carcinomas. Rom J Morphol Embryol. 2012;53(1):89-93.

8. Gonzalez-Moles MA, Galindo P, Gutierrez-Fernandez J, Sanchez-Fernandez E, Rodriguez-Archilla A, Ruiz-Avila I, Bravo M. P53 protein expression in oral squamous cell carcinoma survival analysis. Anticancer Res. 2001:21(4B):2889-94

9. Abrahao AC, Bonelli BV, Nunes FD, Dias EP, Cabral MG. Immunohistochemical expression of p53, p16 and hTERT in oral squamous cell carcinoma and potentially malignant disorders. Braz Oral Res. 2011;25(1):34-41.

10. Etemad-Moghadam S, Keyhani A, Yazdani K, Alaeddini M. Status of p53 and p27 (KIP1) in Iranian patients with oral squamous cell carcinoma. Iran Red Crescent Med J. 2015;17(10):e19359.

11. Dave KV, Chalishazar M, Dave VR, Panja P, Singh M, Modi TG. Immunohistochemical expression of p53 and its clinicopathological correlation with modified Anneroth's histological grading system. J Oral Maxillofac Pathol. 2016;20(1):29-35.

12. Monteiro LS, Diniz-Freitas M, Garcia-Caballero T, Warnakulasuriya S, Forteza J, Fraga M. Combined cytoplasmic and membranous EGFR and p53 overexpression is a poor prognostic marker in early stage oral squamous cell carcinoma. J Oral Pathol Med. 2012;41(7):559-67.

13. Almangush A, Heikkinen I, Mäkitie AA, Coletta RD, Läärä E, Leivo I, Salo T. Prognostic biomarkers for oral tongue squamous cell carcinoma: a systematic review and meta-analysis. Br J Cancer. 2017;117(6):856-66. 